Polymer Journal, Vol. 3, No. 3, pp 403-413 (1972)

\title{
The Chemical Shifts of Poly(vinyl chloride) and Its Model Compounds
}

\author{
Isao Ando, Atsuo Nishioka, and Shōsuke Watanabe \\ Department of Polymer Engineering, Tokyo Institute of Technology, \\ 12-1 Ookayama 2-chome, Meguro-ku, Tokyo, Japan.
}

(Received October 30, 1971)

\begin{abstract}
The proton chemical shifts of meso and racemic 2, 4-dichloropentanes (DCP) were calculated by taking into account the diamagnetic shielding, bond anisotropy and polar effects, using preferred comformations of $T G$ and $G^{\prime} T$ forms for meso DCP, and $T T$ and $G G$ forms for racemic DCP. The $T T$ form was found to be more stable the $G G$ one by $1.97 \mathrm{kcal} / \mathrm{mol}$. It is predicted theoretically that the anti methylene proton would appear at higher field than the syn proton. Also the orders of the excess charges of the $2 p$ electrons and the total charges on the carbon atoms of meso and racemic DCP's coincide with the order of the observed C-13 chemical shifts of those DCP's.

The proton chemical shifts of poly(vinyl chloride) (PVC) were calculated assuming the preferred conformations, $(T G)_{n}$ and $\left(G^{\prime} T\right)_{n}$ for isotactic PVC and $(T T)_{n}$ for syndiotactic PVC. The calculated chemical shifts of racemic methylene and isotactic methine protons appear at a higher field than the meso methylene and syndiotactic methine protons, respectively. As for the isotactic PVC the anti proton appears at higher field than the syn proton just as for DCP.
\end{abstract}

KEY WORDS Poly(vinyl chloride) / Dichloropentane / Chemical Shift / Conformation / Extended Hückel Method /

The proton NMR spectrum of poly(vinyl chloride) (PVC) in solution has long been studied for the stereochemical structure of this polymer, sometimes using decoupling and selective deuteration techniques. ${ }^{1-16}$ Recently Heatley, ${ }^{16}$ et al., have studied the vicinal coupling constants of PVC, using a 220-MHz NMR spectrometer and have suggested that in thermodynamically good solvents, the isotactic dyads are in approximate equilibrium between the conformations which result in a $3_{1}$ helix, whereas syndiotactic dyads are probably in a planar zigzag structure. Also, as the model compounds of PVC, the molecular structure of meso and racemic 2, 4-dichloropentanes (DCP) and isotactic, heterotactic and syndiotactic 2, 3, 6-trichloroheptanes have been studied by infra-red and NMR methods ${ }^{17-24}$ and it has been proposed that the $T G$ and $G^{\prime} T$ forms are preferred for meso DCP, whereas the preferred form for racemic DCP are predominantly $T T$, and also $G G$ with some probabilities. Flory, et al. ${ }^{25}$ have pointed out the existence of less-favoured conformations. However, these may be almost ignored in our discussion described below.

As described above, the molecular structures of DCP and PVC have been studied in detail, but the relationship between the chemical shifts and molecular structures of these compounds have been scarcely studied theoretically. In this paper the calculation of the proton and C-13 chemical shifts of these model compounds in their preferred conformations are described.

At first, in the cases of DCP's the extended Hückel theory ${ }^{26}$ was applied to calculate the total electron energies, the total net charges and the excess charges of $2 p$ electrons. Then the proton chemical shifts of these compounds were calculated by taking into account the contributions from diamagnetic shielding, magnetic anisotropy and polar effects, and were compared with the observed ones. Also the $\mathrm{C}-13$ chemical shifts were calculated and compared with the observed results.

On the basis of these calculations of the model compounds, the proton chemical shifts of isotactic and syndiotactic PVC's were calculated by taking into account the contributions from the 
bond anisotropy and polar effects, and compared with the observed results.

\section{THEORETICAL}

For the molecules (DCP and PVC) under consideration, the proton shielding constant $\sigma_{\mathrm{H}}$ for a proton A can be calculated approximately by a sum of the following terms ${ }^{27,33}$ neglecting the ring current effect,

$$
\sigma_{\mathrm{H}}=\sigma_{\mathrm{H}}^{\mathrm{dia}}+\sigma_{\mathrm{H}}^{\mathrm{para}}+\sum_{\mathrm{B}(\neq \mathrm{A})} \sigma_{\mathrm{AB}}+\sigma_{\mathrm{E}}
$$

where $\sigma_{\mathrm{H}}^{\mathrm{dia}}$ is the diamagnetic shielding term on the specified proton, $\sigma_{\mathrm{H}}{ }^{\text {para }}$ the paramagnetic contribution on the proton, $\sigma_{\mathrm{AB}}$ the neighbour anisotropy effect arising from locally induced currents on the atom B's other than $\mathrm{A}$ in the molecule, and $\sigma_{\mathrm{E}}$ the polar effect arising from the electric field due to any polar group in the molecule.

The value of $\sigma_{\mathrm{H}}^{\text {dia }}$ is given by the well-known formula $^{28}$

$$
\sigma_{\mathrm{H}}^{\mathrm{dia}}=\left(e^{2} / 3 m c^{2}\right) \sum_{i}\left\langle r_{\mathrm{i}}^{-1}\right\rangle
$$

where $e$ is the electron charge, $m$ the mass of the electron, $C$ the velocity of light, $\left\langle r_{\mathrm{i}}^{-1}\right\rangle$ is the mean value of $1 / r_{i}, r_{i}$ the distance between $i$-th electron and the nucleus, and the summation is done over all the electrons on the atom considered. This gives immediately a linear correlation with the electron density around the proton as follows ${ }^{28}$

$$
\sigma_{\mathrm{H}}^{\mathrm{dia}}=k \rho
$$

where $\rho$ is the electron density on the proton and we used $17.8 \mathrm{ppm}^{27}$ as the value of $k$.

The paramagnetic term $\sigma_{\mathrm{HI}}{ }^{\text {para }}$ is neglected as usually due to the small contribution to the proton chemical shift. ${ }^{27}$

The neighbour anisotropy term $\sigma_{A B}$ can be estimated as follows ${ }^{29}$

$$
\sigma_{\mathrm{AB}}=\frac{\Delta \chi_{\mathrm{B}}}{3 r_{\mathrm{AB}}^{3}}\left(1-3 \cos ^{2} \theta\right)
$$

where $\Delta \chi_{\mathrm{B}}\left(=\chi_{\mathrm{B}} \|-\chi_{\mathrm{B}}{ }^{\perp}\right)$ is the magnetic anisotropy of the $B$ atom and $\theta$ is the angle between the anisotropy axis and the internuclear vector $r_{\mathrm{AB}}$. However we used the following equation ${ }^{30}$ of the magnetic anisotropy of the $X-Y$ bond in- stead of eq 4 because of the difficulties in directly estimating on the neighbour anisotropy effect in long chain molecules

$$
\sigma_{X-Y}=\frac{\Delta \chi_{X-Y}}{3 r^{3}}\left(1-3 \cos ^{2} \theta_{M}\right)
$$

where $\Delta \chi_{X-Y}$ is the magnetic anisotropy of the $X-Y$ bond, $r$ the distance between any specified nucleus and the magnetic anisotropy $\Delta \chi$, and $\theta_{\mathrm{M}}$ the angle which the direction of $r$ makes with the $X-Y$ bond. Here we assume the point dipole to be located at the midpoint along the $X-Y$ bond. We took into account the magnetic anisotropies of the $\mathrm{C}-\mathrm{C}$ and $\mathrm{C}-\mathrm{Cl}$ bonds, but neglected $\Delta \chi_{\mathrm{C}-\mathrm{H}}$ because of its small contribution. $^{30}$ So far, various values for $\Delta \chi_{\mathrm{C}-\mathrm{C}}$ are reported, but the most reliable value is not known at present. For the comparison we used for $\Delta \chi_{\mathrm{C}-\mathrm{C}}$ both values of $5.5 \times 10^{-30} \mathrm{~cm}^{330}$ and $9.1 \times$ $10^{-30} \mathrm{~cm}^{3},{ }^{31}$ and used $5.0 \times 10^{-30} \mathrm{~cm}^{332}$ for $\Delta \chi_{\mathrm{C}-\mathrm{Cl} 1}$.

The value of $\sigma_{\mathrm{E}}$ is estimated by the Buckingham's equation $^{33}$

$\sigma_{\mathrm{E}}=-1.48 \times 10^{-12} \frac{q}{R^{2}} E_{\mathrm{z}}-0.74 \times 10^{-18} E^{2}$

where $R$ is a distance between any specified proton and an atom (X) bonded to it, $q$ the charge on the atom $(\mathrm{X})$, and $E_{\mathrm{z}}$ is the component of a uniform electric field $E$ in the bond direction of any specified proton. $E_{z}$ and $E$ were estimated from the charge distributions obtained by the extended Hückel method as described below.

Generally the chemical shift of a particular molecule is affected by the surrounding molecules, which may be of the same or different species, as in the liquid state or a solvent respectively. However it is theoretically very difficult to estimate exactly the solvent effect on polymer molecules. Thus we neglected the solvent effect in a first approximation.

The net charge distributions and the total electron energies of the $T G\left(G^{\prime} T\right)$ form for meso DCP are calculated by the extended Hückel theory. ${ }^{26}$ In this calculation the various Coulomb integrals $\left(H_{\mathrm{rr}}\right)$ are taken as the appropriate valance-state ionization potential for the particular atomic orbital under consideration that is, $\mathrm{H}_{\mathrm{rr}}\left(\mathrm{H}_{1 \mathrm{~s}}\right)=-13.6 \mathrm{eV}, \mathrm{H}_{\mathrm{rr}}\left(\mathrm{C}_{2 \mathrm{~s}}\right)=-21.43 \mathrm{eV}, \mathrm{H}_{\mathrm{rr}}$ $\left(\mathrm{C}_{2 \mathrm{p}}\right)=-11.42 \mathrm{eV}, \quad \mathrm{H}_{\mathrm{rr}}\left(\mathrm{Cl}_{3 \mathrm{~s}}\right)=-25.26 \mathrm{eV} \quad$ and 
$\mathrm{H}_{\mathrm{rr}}\left(\mathrm{Cl}_{3 \mathrm{p}}\right)=-15.09 \mathrm{eV},{ }^{34}$ where in $\mathrm{H}_{\mathrm{rr}}\left(\mathrm{X}_{\mathrm{Y}}\right), \mathrm{X}$ and $\mathrm{Y}$ denote any atomic symbol and the electron orbital state of atom $\mathrm{X}$, respectively. The resonance integral $\left(\mathrm{H}_{\mathrm{rs}}\right)$ is taken as follows.

$$
\mathrm{H}_{\mathrm{rs}}=\frac{\mathrm{K}}{2}\left(\mathrm{H}_{\mathrm{rr}}+\mathrm{H}_{\mathrm{ss}}\right) \mathbf{S}_{\mathrm{rs}}
$$

where the $\mathrm{K}$ is a constant which was assigned a value of $1.75^{26}$ and $S_{r s}$ is the overlap integral. The Slater's effective nuclear charges used for $\mathrm{H}, \mathrm{C}$, and $\mathrm{Cl}$ atoms are 1.1, 3.25 and 6.10, respectively. In this calculation, the iteration is performed until the total electron energy of molecule under consideration converges.

The rotational isomeric states of trans $(T)$, and two gauches $\left(G\right.$ and $G^{\prime}$ ) are defined as occurring at the rotational angles $0^{\circ}, 120^{\circ}$ and $240^{\circ}$, respectively, by the clockwise rotation around the $\mathrm{C}-\mathrm{C}$ bond as expressed in the Newman projection. The $\mathrm{C}-\mathrm{C}, \mathrm{C}-\mathrm{H}$ and $\mathrm{C}-\mathrm{Cl}$ bond length ${ }^{35}$ used are set to $1.54,1.10$ and $1.69 \AA$, respectively, and each of the $\mathrm{C}-\mathrm{C}-\mathrm{C}, \mathrm{C}-\mathrm{C}-\mathrm{H}$ and $\mathrm{C}-$ $\mathrm{C}-\mathrm{Cl}$ bond angles used is set to $109^{\circ} 28^{\prime}$.

\section{RESULTS AND DISCUSSION}

\section{Meso and Racemic 2, 4-Dichloropentanes}

The net charge distributions and the total electron energies of the $T G$ form for meso DCP, and the $T T$ and $G G$ forms for racemic DCP calculated by the extended Hückel theory are shown in Figure 1, where one of the methyl protons was assumed to take the trans position against the central carbon atom, and the net charges on the three hydrogen atoms of the methyl group were averaged taking into account its free rotation. As shown in Figure 1 the total electron energy of the $T T$ form in racemic DCP is $1.97 \mathrm{kcal} / \mathrm{mol}$ lower than the $G G$ form. This value is in well accordance with that of 1.7$2.3 \mathrm{kcal} / \mathrm{mol}$ by the van der Waals and electrostatic interaction, ${ }^{19}$ and of $1.5 \mathrm{kcal} / \mathrm{mol}$ by NMR ${ }^{21}$ Moreover, the total electron energies of meso and racemic DCP's show that racemic DCP is much more stable than meso DCP. This is in close agreement with the results calculated by McMahon, et al. ${ }^{21}$ assuming Lennard-Jones type interactions between nonbonded atoms.

Using these results and, eq 1, 3, 5, and 6, the proton magnetic shielding constants of DCP's (a)

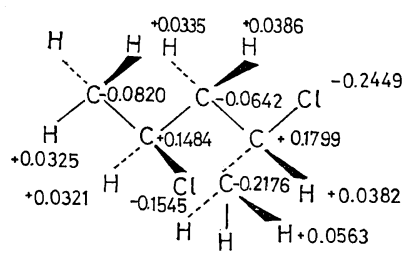

(TG)

T.E. $=-776.99206 \mathrm{eV}$

(b)

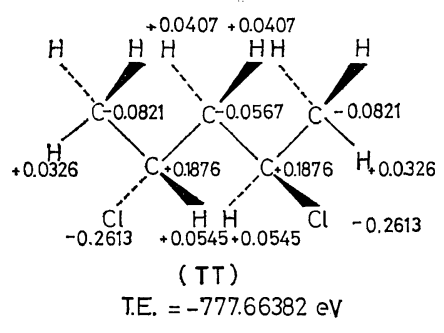

(c)

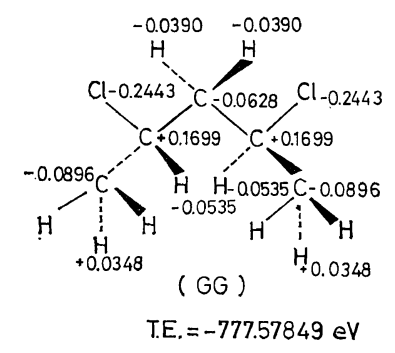

Figure 1. The charge distributions and total electron energies (T.E.) of 2,4-dichloropentanes. (a) meso, $T G$; (b) racemic, $T T$; (c) racemic, GG.

are estimated and tabulated in Tables I and II, in which the magnetic shielding constant for the methyl group is averaged on the three methyl protons and the values in the bracket are those obtained by using $9.1 \times 10^{-30} \mathrm{~cm}^{3}$ as $\Delta \chi_{\mathrm{C}_{-\mathrm{C}}}$. We calculated $E$ and $E_{z}$ with the point dipole approximation. The dipole moment of the $\mathrm{C}-\mathrm{Cl}$ bond used was 1.72 Debye unit $(D)$ which was averaged over all values calculated by the charge distribution of the preferred conformation. The chemical shifts $\left(\sigma_{\mathrm{AV}}\right)$ of each proton were averaged for the preferred conformations using the following equations. 


\section{Ando, A. Nishioka, and S. Watanabe}

Table I. The calculated proton chemical shifts of meso 2, 4-Dichloropentane

\begin{tabular}{|c|c|c|c|c|c|}
\hline & \multicolumn{5}{|c|}{ Averaged over the preferred $T G$ and $G^{\prime} T$ conformations (at room temp) (ppm) } \\
\hline & $\mathrm{CH}_{3}$ & anti & $\mathrm{CH}_{2}$ & syn & $\mathrm{CH}$ \\
\hline$\sigma^{\text {dia }}$ & 17.009 & 17.203 & & 17.112 & 17.175 \\
\hline$\sigma_{\mathrm{C}-\mathrm{C}^{\mathrm{a}}}$ & $\begin{array}{l}-0.293 \\
(-0.486)\end{array}$ & $\begin{array}{l}-0.583 \\
(-0.965)\end{array}$ & & $\begin{array}{l}-0.782 \\
(-1.294)\end{array}$ & $\begin{array}{l}-0.598 \\
(-0.989)\end{array}$ \\
\hline$\sigma_{\mathrm{C}-\mathrm{C} 1}$ & -0.009 & -0.071 & & +0.103 & -0.370 \\
\hline$\sigma \mathrm{E}$ & -0.204 & -0.341 & & -0.409 & -1.790 \\
\hline$\sigma$ Proton & $\begin{array}{c}16.503 \\
(16.310)\end{array}$ & $\begin{array}{c}16.208 \\
(15.826)\end{array}$ & & $\begin{array}{c}16.029 \\
(15.517)\end{array}$ & $\begin{array}{c}14.417 \\
(14.026)\end{array}$ \\
\hline$\Delta \sigma_{\text {Proton }}{ }^{b}$ & \multicolumn{2}{|c|}{$\begin{array}{c}0.295 \\
(0.484)\end{array}$} & $\begin{array}{c}0.179 \\
(0.309)\end{array}$ & \multicolumn{2}{|c|}{$\begin{array}{l}1.612 \\
(1.491)\end{array}$} \\
\hline
\end{tabular}

a $\sigma_{\mathrm{C}-\mathrm{C}}, \Delta \chi_{\mathrm{C}-\mathrm{C}}=5.5 \times 10^{-30} \mathrm{~cm}^{3} ;(), \Delta \chi_{\mathrm{C}-\mathrm{C}}=9.1 \times 10^{-30} \mathrm{~cm}^{3}$.

b $\Delta \sigma$ 's denote difference between the $\mathrm{CH}_{3}$ and $\mathrm{CH}_{2}$, the anti and syn protons, and the $\mathrm{CH}_{2}$ and $\mathrm{CH}$, respectively.

Table II. The calculated proton chemical shifts of racemic 2, 4-dichloropentane

\begin{tabular}{|c|c|c|c|c|c|c|c|c|c|}
\hline & \multicolumn{6}{|c|}{ Preferred conformation } & \multirow{2}{*}{\multicolumn{3}{|c|}{$\begin{array}{l}\text { Averaged over the preferred } \\
T T \text { and } G G \text { conformations } \\
\text { (at room temp) (ppm) }\end{array}$}} \\
\hline & \multicolumn{3}{|c|}{$T T$ (ppm) } & \multicolumn{3}{|c|}{$G G(\mathrm{ppm})$} & & & \\
\hline & $\mathrm{CH}_{3}$ & $\mathrm{CH}_{2}$ & $\mathrm{CH}$ & $\mathrm{CH}_{3}$ & $\mathrm{CH}_{2}$ & $\mathrm{CH}$ & $\mathrm{CH}_{3}$ & $\mathrm{CH}_{2}$ & $\mathrm{CH}$ \\
\hline$\sigma^{\text {dia }}$ & 17.219 & 17.076 & 16.831 & 17.179 & 17.106 & 16.848 & 17.218 & 17.076 & 16.831 \\
\hline$\sigma_{\mathrm{C}-\mathrm{C}^{\mathrm{a}}}$ & $\begin{array}{l}-0.318 \\
(-0.526)\end{array}$ & $\begin{array}{l}-0.484 \\
(-0.801)\end{array}$ & $\begin{array}{l}-0.634 \\
(-1.049)\end{array}$ & $\begin{array}{l}-0.220 \\
(-0.364)\end{array}$ & $\begin{array}{l}-0.667 \\
(-1.094)\end{array}$ & $\begin{array}{l}-0.485 \\
(-0.802)\end{array}$ & $\begin{array}{l}-0.314 \\
(-0.521)\end{array}$ & $\begin{array}{l}-0.490 \\
(-0.779)\end{array}$ & $\begin{array}{l}-0.629 \\
(-1.040)\end{array}$ \\
\hline$\sigma_{\mathrm{C}-\mathrm{C} 1}$ & +0.090 & -0.071 & -0.248 & -0.051 & +0.101 & -0.404 & +0.085 & -0.066 & -0.253 \\
\hline$\sigma \mathrm{E}$ & -0.177 & -0.354 & -1.645 & -0.396 & -0.409 & -1.687 & -0.184 & -0.355 & -1.647 \\
\hline$\sigma$ Proton & $\begin{array}{c}16.814 \\
(16.606)\end{array}$ & $\begin{array}{c}16.167 \\
(15.850)\end{array}$ & $\begin{array}{c}14.304 \\
(13.889)\end{array}$ & $\begin{array}{c}16.512 \\
(16.368)\end{array}$ & $\begin{array}{c}16.137 \\
(15.704)\end{array}$ & $\begin{array}{c}14.272 \\
(13.955)\end{array}$ & $\begin{array}{l}16.805 \\
(16.598)\end{array}$ & $\begin{array}{l}16.165 \\
(15.876)\end{array}$ & $\begin{array}{c}14.302 \\
(13.891)\end{array}$ \\
\hline$\Delta \sigma$ Proton $^{b}$ & \multicolumn{3}{|c|}{$\begin{array}{cc}0.647 & 1.863 \\
(0.756) & (1.961)\end{array}$} & \multicolumn{3}{|c|}{$\begin{array}{cc}0.375 & 1.865 \\
(0.664) & (1.749)\end{array}$} & \multicolumn{2}{|c|}{$\begin{array}{cc}0.640 & 1 \\
(0.722) & (1\end{array}$} & $\begin{array}{l}1.863 \\
1.985)\end{array}$ \\
\hline
\end{tabular}

a $\sigma_{\mathrm{C}-\mathrm{C}}, \Delta \chi_{\mathrm{C}-\mathrm{C}}=5.5 \times 10^{-30} \mathrm{~cm}^{3} ;(), \Delta \chi_{\mathrm{C}-\mathrm{C}}=9.1 \times 10^{-30} \mathrm{~cm}^{3}$.

b $\Delta \sigma$ 's denote the differences between the $\mathrm{CH}_{3}$ and $\mathrm{CH}_{2}$, and the $\mathrm{CH}_{2}$ and $\mathrm{CH}$, respectively.

$$
\begin{aligned}
& \sigma_{\mathrm{a} \nabla}=\sum X_{i} \sigma_{i} \\
& X_{i}=\mathrm{e}^{-\Delta E_{\mathrm{i}} / R T} / \sum \mathrm{e}^{-\Delta E_{\mathrm{i}} / R T}
\end{aligned}
$$

where $\sigma_{i}$ and $X_{i}$ are the chemical shift and fraction of the $i$-th preferred conformation, $\Delta E_{\mathrm{i}}=$ $E_{\mathrm{i}}-E_{0}, E_{0}$ being the energy of the conformation taken as the reference state and $E_{i}$ the energy of the $i$-th preferred conformation. The sum is taken over all the important conformers. $R$ and $T$ are the gas constant and absolute temperature, respectively.

From Tables I and II it was found that the polar effect contributes predominantly to the relative chemical shift difference as compared with the other terms and the contribution of the diamagnetic terms to the relative chemical shift difference is very small.
Table III. The observed proton chemical shifts of racemic and meso 2, 4-dichloropentanes

\begin{tabular}{|c|c|c|c|c|}
\hline & \multicolumn{4}{|c|}{ Chemical shift (ppm) } \\
\hline & \multirow{2}{*}{$\mathrm{CH}_{3}$} & \multicolumn{2}{|c|}{$\mathrm{CH}_{2}$} & \multirow{2}{*}{$\mathrm{CH}$} \\
\hline & & A & B & \\
\hline \multicolumn{5}{|l|}{ Racemic } \\
\hline$\sigma_{\text {Proton }}^{\text {obs }}$ & 8.57 & \multicolumn{2}{|c|}{8.11} & 5.81 \\
\hline$\Delta \sigma_{\text {Proton }}^{\text {obs }}$ & & 0.46 & 2.30 & \\
\hline \multicolumn{5}{|l|}{ Meso } \\
\hline$\sigma_{\text {Proton }}^{\text {obs }}$ & 8.49 & 8.05 & 7.75 & \\
\hline$\Delta \sigma_{\text {Proton }}^{\text {obs }}$ & \multicolumn{2}{|c|}{0.44} & \multicolumn{2}{|c|}{1.82} \\
\hline
\end{tabular}
(at $20^{\circ} \mathrm{C}$ and $\left.60 \mathrm{MHz}\right)^{\mathrm{a}}$

a The reference is TMS. $\Delta \sigma$ 's denote the differences between the $\mathrm{CH}_{3}$ and $\mathrm{CH}_{2}$, the anti and syn protons, and the $\mathrm{CH}_{2}$ and $\mathrm{CH}$, respectively. 


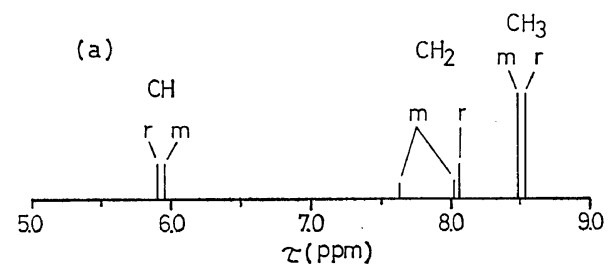

(b)

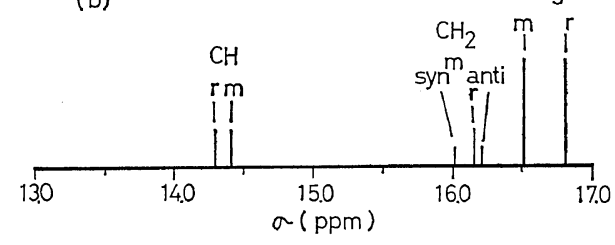

(c)
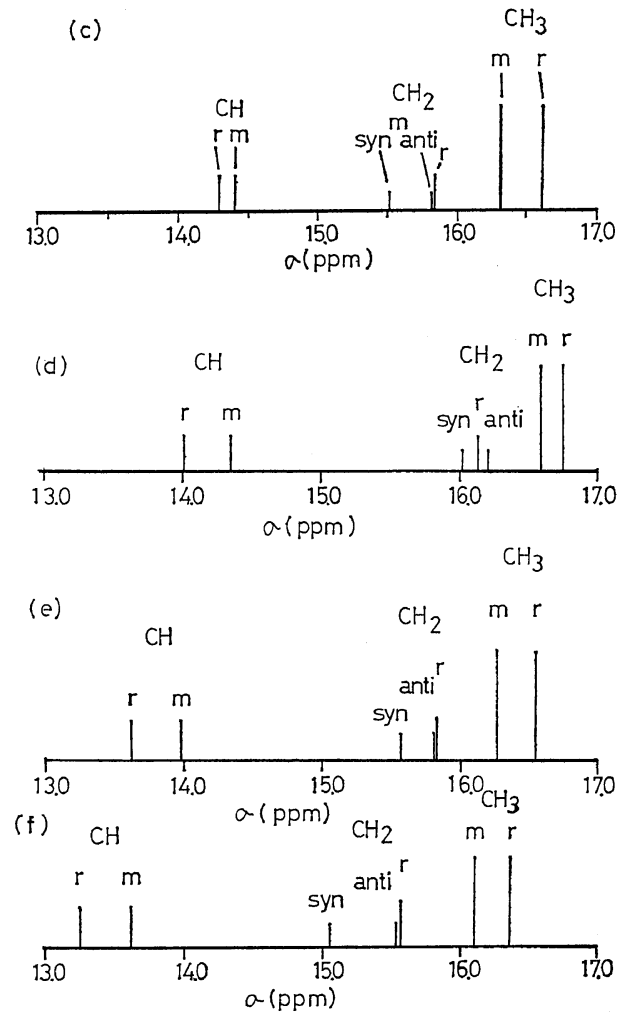

Figure 2. The stick spectra of 2,4-dichloropentanes: (a) observed 20 ; (b) calculated, $\Delta \chi_{\mathrm{C}-\mathrm{C}}=5.5 \times 10^{-30}$ $\mathrm{cm}^{3}, \Delta \chi_{\mathrm{C}-\mathrm{Cl}}=5.0 \times 10^{-30} \mathrm{~cm}^{3}$, and $\mu_{\mathrm{C}-\mathrm{Cl}}=1.72 D$; (c) calculated, $\Delta \chi_{\mathrm{C}-\mathrm{C}}=9.1 \times 10^{-30} \mathrm{~cm}^{3}, \quad \Delta \chi_{\mathrm{C}-\mathrm{C} 1}=5.0 \times$ $10^{-30} \mathrm{~cm}^{3}$, and $\mu_{\mathrm{C}-\mathrm{Cl}}=1.72 D$; (d) calculated $\Delta \chi_{\mathrm{C}-\mathrm{C}}=$ $5.5 \times 10^{-30} \mathrm{~cm}^{3}, \Delta \chi_{\mathrm{C}-\mathrm{Cl} 1}=5.0 \times 10^{-30} \mathrm{~cm}^{3}$, and $\mu_{\mathrm{C}-\mathrm{Cl}}=$ $1.86 D$; (e) calculated, $\Delta \chi_{\mathrm{C}-\mathrm{C}}=9.1 \times 10^{-30} \mathrm{~cm}^{3}, \Delta \chi_{\mathrm{C}-\mathrm{C} 1}$ $=5.0 \times 10^{-30} \mathrm{~cm}^{3}$, and $\mu_{\mathrm{C}-\mathrm{Cl}}=1.86 \mathrm{D}$; (f) calculated, $\Delta \chi_{\mathrm{C}-\mathrm{C}}=12.0 \times 10^{-30} \mathrm{~cm}^{3}, \Delta \chi_{\mathrm{C}-\mathrm{Cl}}=5.0 \times 10^{-30} \mathrm{~cm}^{3}$, and $\mu_{\mathrm{C}-\mathrm{C} 1}=1.86 D$.
The chemical shifts of meso and racemic DCP's observed by Tincher $^{20}$ are shown in Table III. For a clear comparison of the observed results with the calculated ones, we showed these results in terms of the stick spectra in Figure 2. It was found that the order of the $\mathrm{CH}_{3}, \mathrm{CH}_{2}$, and $\mathrm{CH}$ protons in meso and racemic DCP's is consistent with the observed one, and the anti proton appears at higher field than the syn proton in meso DCP. The racemic $\mathrm{CH}_{3}, \mathrm{CH}_{2}$, and meso $\mathrm{CH}$ protons appear at higher fields than the meso $\mathrm{CH}_{3}$ and $\mathrm{CH}_{2}$ protons, and the racemic $\mathrm{CH}$ protons, respectively. When both of the calculated results (b) and (c) are compared with the observed ones (a), the appearance of the order of the methylene protons is better explained by (c) than by (b). This means that greater than $5.5 \times 10^{-30} \mathrm{~cm}^{3}$ is better value for $\Delta \chi_{\mathrm{C}-\mathrm{C}}$ in this case, On the other hand, as for the difference in chemical shift between $\mathrm{CH}$ and $\mathrm{CH}_{2}$ protons, both of (b) and (c) are not good. Because of the larger polar effect due to $\mu_{\mathrm{C}-\mathrm{Cl}}$, the chemical shift of $\mathrm{CH}$ proton should be sensitive to the value of $\mu_{\mathrm{C}-\mathrm{Cl}}$. Then the difference in the values for calculated chemical shift between $\mathrm{CH}$ and $\mathrm{CH}_{2}$ protons which was smaller than the observed value will be improved by adjusting the value of $\mu_{\mathrm{C}-\mathrm{Cl}}$. The value of $\mu_{\mathrm{C}-\mathrm{Cl}}$ to obtain the plausible values of difference in the chemical shift between the $\mathrm{CH}$ and $\mathrm{CH}_{2}$ protons of racemic $\mathrm{DCP}$ was found to be $1.86 \mathrm{D}$, where in this calculation the electric charge, $\mu_{\mathrm{C}-\mathrm{Cl}} / r_{\mathrm{C}-\mathrm{Cl}}$, instead of $\mu_{\mathrm{C}-\mathrm{Cl}}$ was changed as the parameter, $r_{\mathrm{C}-\mathrm{Cl}}$ being the bond length between the $\mathrm{C}$ and $\mathrm{Cl}$ atoms. The spectrum (d) was obtained by using $5.5 \times 10^{-30} \mathrm{~cm}^{3}$ as $\Delta \chi_{\mathrm{C}-\mathrm{C}}$. The calculated chemical shifts of $\mathrm{CH}_{2}$ protons don't coincide with the observed ones. In the spectra (e) and (f) using $9.1 \times 10^{-30} \mathrm{~cm}^{3}$ and $12.0 \times 10^{-30} \mathrm{~cm}^{3}$ as $\Delta \chi_{\mathrm{C}-\mathrm{C}}$, respectively, the calculated chemical shifts of meso and racemic $\mathrm{CH}_{2}$ protons become close to the observed ones. Thus the magnitude of $\Delta \chi_{\mathrm{C}-\mathrm{C}}$ plays an important role for the chemical shifts of the $\mathrm{CH}_{2}$ protons. As for $\Delta \chi_{\mathrm{C}-\mathrm{Cl}}$, the deviation of $\Delta \chi_{\mathrm{C}-\mathrm{Cl}}$ from $5.5 \times 10^{-30} \mathrm{~cm}^{3}$ did not given the large influence on the chemical shift in comparison with the case of $\Delta \chi_{\mathrm{C}-\mathrm{C}}$. As shown in Figure 2(d)-(f) the agreement between the calculated and observed chemical shifts $\delta\left(\mathrm{CH}_{2}-\right.$ $\mathrm{CH})$ was improved by using $1.86 \mathrm{D}$ as the value 
of $\mu_{\mathrm{C}-\mathrm{C} 1}$; but with this better agreement the difference in the values for calculated chemical shifts between the meso and racemic protons of $\mathrm{CH}_{3}$ or $\mathrm{CH}$ group are much larger than the observed values. These discrepancies would be partly attributable to our model based on the isolated molecule, and the neglect of the effect of the medium or solvent and so on. Further improvements will be necessary.

Recently the C-13 chemical shifts of meso and racemic DCP's were measured ${ }^{36,37}$ and it was found that each carbon nuclei of meso DCP appears at a higher field than those of racemic DCP. Yonezawa, et al. ${ }^{38}$ have shown theoretically that the shielding constant of carbon nuclei in saturated hydrocarbons is roughly proportional to the excess charge of the $2 p$ electrons. Thus the total net charges and the excess charges of the $2 p$ electrons of DCP calculated above are shown in Table IV together with the observed C-13 chemical shifts reproduced from our previous paper. ${ }^{37}$ The calculated results showing that each meso carbon appears at higher field than a racemic carbon, agree with the observed results. To show clearly these relationships, the chemical shifts plotted against the total net charges and the excess charges of the $2 p$ electrons are shown in Figure 3, where the reference signal is ${ }^{13} \mathrm{CH}_{3} \mathrm{OH}$. It is found that

Table IV. The total net charges, excess (or deficient) charges of $2 p$ electrons on the carbon atoms, and $\mathrm{C}-13$ chemical shifts for meso and racemic 2,4-dichloropentanes

\begin{tabular}{cccc}
\hline & $\begin{array}{c}\text { Total net } \\
\text { charge }^{\mathrm{a}}\end{array}$ & $\begin{array}{c}\text { Excess (or } \\
\text { deficient) charges } \\
\text { of } 2 p \text { electrons }^{\mathrm{a}}\end{array}$ & $\begin{array}{c}\mathrm{C}-13 \\
\text { chemical }^{\text {shift }} \text { (ppm) }\end{array}$ \\
\hline Meso & & & \\
$\mathrm{CH}_{3}$ & -0.1498 & +0.0489 & +23.60 \\
$\mathrm{CH}_{2}$ & -0.0642 & +0.1160 & -2.20 \\
$\mathrm{CH}$ & +0.1642 & +0.1589 & -6.55 \\
Racemic & & & \\
$\mathrm{CH}_{3}$ & -0.0823 & +0.1149 & +22.60 \\
$\mathrm{CH}_{2}$ & -0.0569 & +0.1231 & -2.32 \\
$\mathrm{CH}$ & +0.1871 & +0.3038 & -7.65 \\
\hline
\end{tabular}

a Averaged by the preferred conformations. The minus and plus signs denote the excess aod deficient charges, respectively.

b The chemical shifts are in parts per million up field from ${ }^{13} \mathrm{CH}_{3} \mathrm{OH}$.

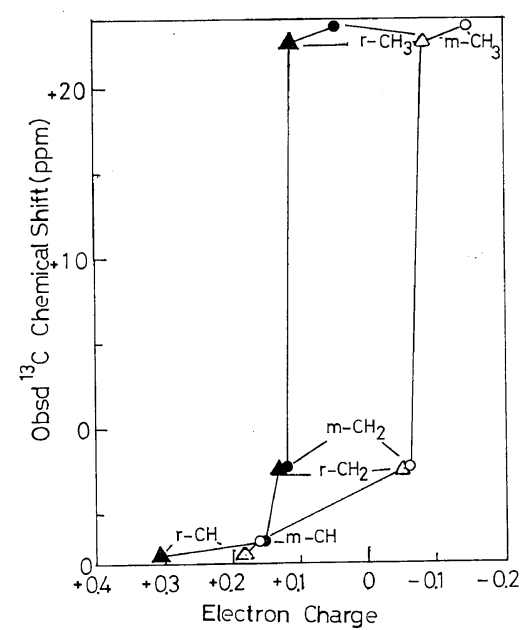

Figure 3. The $\mathrm{C}-13$ chemical shifts versus the total charges $(\bigcirc$, meso and $\triangle$, racemic) and excess charges of $2 p$ electrons ( $\boldsymbol{O}$, meso and $\boldsymbol{\Lambda}$, racemic) on the carbon atoms.

the chemical shift appears at a higher field with increasing the total net charge or the excess charges of the $2 p$ electrons, though there is not a linear relationship between them. As for the causes of the discrepancy it may be suggested that Yonezawa, et al. ${ }^{38}$ derived a linear relationship between the $\mathrm{C}-13$ chemical shift and the excess charge of the $2 p$ electrons taking into account only the diamagnetic and paramagnetic terms, but did not consider the magnetic anisotropy of the $\mathrm{C}-\mathrm{C}$ bonds. Another weak point may be considered in our calculation based on the extended Hückel theory. The improvements of these points will be necessary in future.

\section{Proton Chemical Shifts of Isotactic and Syndio- tactic PVC's}

The unique character which characterizes a linear polymer from a simple molecule is the diversity of the stereospecific conformations and configurations of the former. Usually, the temperature dependence of the chemical shifts of a small molecule in solution can be attributed mainly to the solvent effect, but that of a linear polymer includes the change of conformation of a polymer chain together with the above effect. The latter could be referred to as an "intrinsic" effect, which should be treated separately from the "external" solvent effect, i.e., the commonly used solvent effect. ${ }^{39}$ 
The Chemical Shifts of DCP and PVC.

In the system under consideration it may be safely said that PVC does not form a $\pi$-complex with solvent and therefore the "external" solvent effect neglected as a first approximation. Here, we will be concerned with only the "intrinsic" solvent effect. The following factors as the "intrinsic" solvent effect are considered: $\sigma_{\mathrm{H}}{ }^{\mathrm{dia}}$, $\sigma_{\mathrm{H}}{ }^{\text {para }}, \sigma_{\mathrm{AB}}$ and $\sigma_{\mathrm{E}}$. It is necessary to calculate $\sigma_{\mathrm{H}}{ }^{\text {dia }}$ when discussing the absolute value of the total shielding, but for a discussion of only the chemical shift difference between the isotactic and syndiotactic polymers, $\sigma_{\mathrm{H}}{ }^{\text {dia }}$ neglected due to the small difference between $\sigma_{\mathrm{H}}{ }^{\text {dia's }}$ of the corresponding meso and racemic DCP's. Also $\sigma_{\mathrm{H}}{ }^{\text {para }}$ neglected as well as in the case of DCP. The calculation of $\sigma_{\mathrm{AB}}$ was approximated by the point dipole method as well as in the case of DCP. $\sigma_{\mathrm{E}}$ was calculated by the Buckingham's equation (eq 6 ) and the same values of $\mu_{\mathrm{C}-\mathrm{Cl}}$ were used as in the case of DCP.

At present we cannot prepare isotactic PVC and it has been reported that polymerization of vinyl chloride under special conditions yields highly syndiotactic PVC, ${ }^{40}$ but its NMR spectrum has not been measured because of its poor solubility. Thus we will be concerned with and discuss the chemical shifts of isotactic and syndiotactic polymers on the basis of those of the corresponding sequences in atactic polymer.

\section{Isotactic PVC}

The chemical shifts of a polymer molecule with any specified preferred conformation will be changed by the following factors: (i) the number of monomer units near any specified atom, (ii) the deviation $(\Delta \varphi)$ from trans and gauche locations, $0^{\circ}$ and $120^{\circ}$ respectively, and (iii) the values of $\Delta \chi_{\mathrm{C}-\mathrm{C}}, \Delta \chi_{\mathrm{C}-\mathrm{Cl} 1}$ and $\mu_{\mathrm{C}-\mathrm{C} 1}$.

At first the dependence of the chemical shifts of the $\mathrm{CH}_{2}$ and $\mathrm{CH}$ protons of isotactic PVC on the number of monomer units $(n)$ contributed by the magnetic anisotropies of the $\mathrm{C}-\mathrm{C}$ and $\mathrm{C}-\mathrm{Cl}$ bonds, and polar effects, using $(T G)_{n}$ as the conformation are shown in Figures 4 and 5, where for example the four-monomer unit model for the $\mathrm{CH}_{2}$ is defined as follows; that is, in order to calculate the chemical shifts of the $i$-th $\mathrm{CH}_{2}$ we took into account the contributions from the $i-2$ th to the $i+4$ th carbon atoms in this model (Figure 6). In this calculation, we

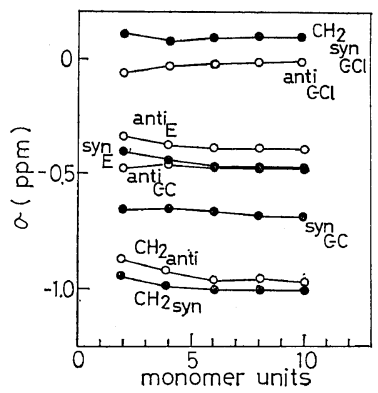

Figure 4. The dependence of the chemical shifts of the $\mathrm{CH}_{2}$ protons in isotactic $\mathrm{PVC}$ on the number of monomer units and the contributions of the $\mathrm{C}-\mathrm{Cl}$ and $\mathrm{C}-\mathrm{C}$ bond anisotropies and the polar effect to them: $\bigcirc$, anti proton; $\bullet$, syn proton. $\sigma_{X_{Y}}$ is the chemical shift of the $X$ proton due to the $Y$ bond or polar effect.

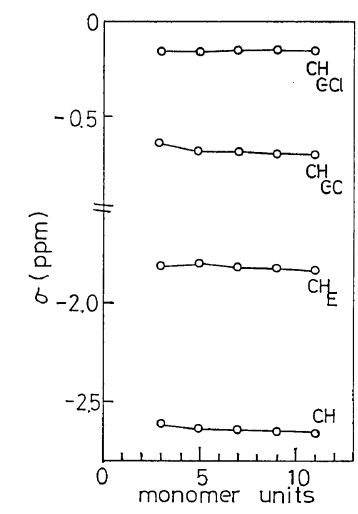

Figure 5. The dependence of the chemical shifts of the $\mathrm{CH}$ in isotactic PVC on the number of monomer units and the contributions of the $\mathrm{C}-\mathrm{Cl}$ and $\mathrm{C}-\mathrm{C}$ bond anisotropies and the polar effect.

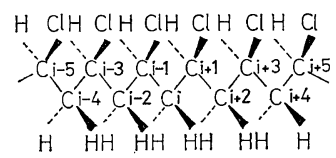

Figure 6. The notation of the structure of poly(vinyl chloride).

used the same values of $\Delta \chi_{\mathrm{C}-\mathrm{C}}, \Delta \chi_{\mathrm{C}-\mathrm{C} 1}$ and $\mu_{\mathrm{C}-\mathrm{C} 1}$ $(1.72 D)$ as the case of DCP. Each proton shift seems to approach a constant value at about four or five monomer units. Therefore the chemical shifts of this polymer may be discussed by a relatively short sequence in a chain. And also 
as expected from the case of DCP, the polar effect contributes predominantly to the chemical shift of the $\mathrm{CH}$ proton. As for the $\mathrm{CH}_{2}$ protons the anti proton appears at higher field than the syn proton as well as the case of meso DCP and both $\Delta \chi_{\mathrm{C}-\mathrm{C}}$ and polar effect contribute predominantly to the chemical shift.

Hereafter we will be concerned with only the 4-5 model for comparison with the observed data of tetrad and pentad tacticities as described below, where the 4-5 model is defined as follows; the numbers of monomer units being taken into account the $\mathrm{CH}_{2}$ and $\mathrm{CH}$ are four and five monomer units, respectively.

So far it has been pointed by studies ${ }^{4}$ on conformational analysis that the preferred locations of the rotational angles of the $T$ and $G$ conformations in the various polymer chains deviate slightly from the positions at $\varphi_{t}=0^{\circ}$ and $\varphi_{\mathrm{g}}=120^{\circ}$, respectively. According to these reports, we have studied the chemical shifts of polypropylene ${ }^{42}$ and results have supported that the small deviation $(\Delta \varphi)$ of $T$ and $G$ from $0^{\circ}$ and $120^{\circ}$, respectively, are reasonable in explaining the chemical shift of polypropylene. Thus the dependence of the proton chemical shift of isotactic PVC on the rotational angle deviation $(\Delta \varphi)$ were calculated using the 4-5 model of isotactic PVC, and typical results are compared with the observed ones as shown in Figure 7(a)(d). The rotational angles are varied in the stable direction of the conformational energy on the basis obtained in the case of polypropylene. ${ }^{42}$ Then it was found that the anti proton appears at higher field than the syn proton in the range from $\Delta \varphi=0^{\circ}$ to $20^{\circ}$, and the chemical shift difference between both protons decreases with increasing $\Delta \varphi$ and becomes closer to the observed value. Although the $\mathrm{CH}$ proton appears at lower field than the $\mathrm{CH}_{2}$ protons, the agreement of the calculated results with the observed ones is not sufficiently quantitative. In these calculations the difference between both results calculated by $5.5 \times 10^{-20}$ and $9.1 \times 10^{-30} \mathrm{~cm}^{2}$ as $\Delta \chi_{\mathrm{C}-\mathrm{C}}$ was small. As the magnitude of $\mu_{\mathrm{C}-\mathrm{Cl}}$ contributes largely to the chemical shift of the $\mathrm{CH}$ proton, we calculated the chemical shift by changing the magnitude of $\mu_{\mathrm{C}-\mathrm{Cl}}$. A closer agreement with the observed values is shown in Figure 7(e) and (f), where the more suitable value of $\mu_{\mathrm{C}-\mathrm{C} 1}$ was

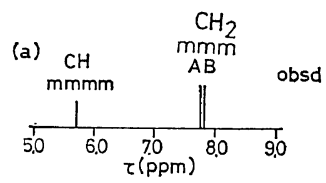

(b)

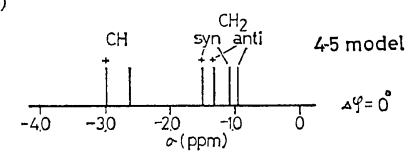

(c)

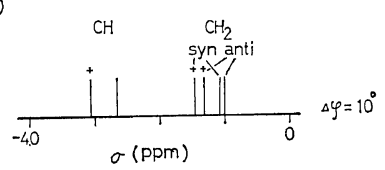

(d)

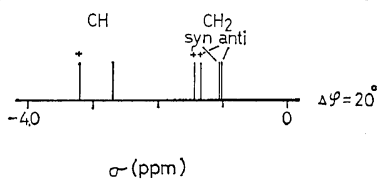

(e)
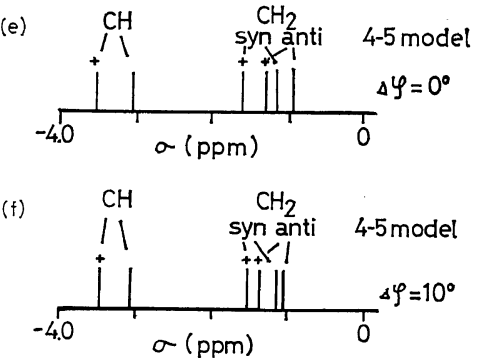

Figure 7. The stick spectra of isotactic poly(vinyl chloride): (a) observed ${ }^{16}$ in pentachloroethane, at $140^{\circ} \mathrm{C}(220 \mathrm{MHz}) ;$ (b)-(d) calculated, $\mu_{\mathrm{C}-\mathrm{Cl}}=1.72 \mathrm{D}$; (e) and (f) calculated, $\mu_{\mathrm{C}-\mathrm{Cl}}=1.84 \mathrm{D} . \quad \mid, \Delta \chi_{\mathrm{C}-\mathrm{C}}=$ $5.5 \times 10^{-30} \mathrm{~cm}^{3} ; \dagger, \Delta \chi_{\mathrm{C}-\mathrm{C}}=9.1 \times 10^{-30} \mathrm{~cm}^{3}$.

1.84D. This valke of $\mu_{\mathrm{C}-\mathrm{C} 1}$ is nearly equal to that $(1.86 D)$ of DCP. The difference in chemical shift between the anti and syn protons at $\Delta \varphi=$ $10^{\circ}$ is in better agreement with the abserved results than those at $\Delta \varphi=0^{\circ}$.

\section{Syndiotactic PVC}

The preferred conformation of syndiotactic PVC, may be considered from the results of its model compound that a planar zigzag and $\{(T T)(G G)(T T)\}_{n}$ forms are preferable. However, the former is much more stable than the latter. Therefore we calculated the chemical shift of only the planar zigzag form. At first the dependence of the chemical shifts on the number 
The Chemical Shifts of DCP and PVC.

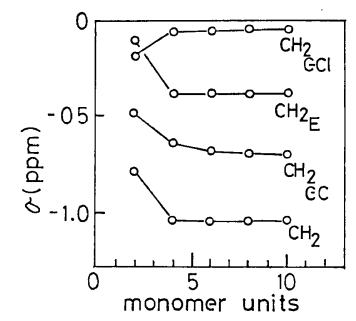

Figure 8. The dependence of the chemical shifts of the $\mathrm{CH}_{2}$ protons in syndiotactic PVC on the number of monomer units and the contributions of the $\mathrm{C}-\mathrm{Cl}$ and $\mathrm{C}-\mathrm{C}$ bond anisotropies and the polar effect.

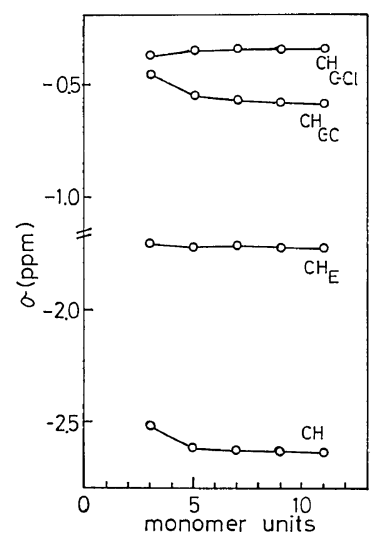

Figure 9. The dependence of the chemical shifts of the $\mathrm{CH}$ proton in syndiotactic PVC on the number of monomer units and the contributions of the $\mathrm{C}-\mathrm{Cl}$ and $\mathrm{C}-\mathrm{C}$ bond anisotropies and the polar effect.

of monomer units is shown in Figures 8 and 9, where $\varphi_{\mathrm{t}}=0^{\circ}$. Each proton chemical shift seems to approach a constant value at about four or five monomer units and the polar effect contributes predominantly to the chemical shift of the $\mathrm{CH}$ proton as well as in the case of isotactic PVC. The $n$ dependence of the chemical shift of the $\mathrm{CH}_{2}$ protons is larger than that of the $\mathrm{CH}$ proton. With the $\mathrm{CH}_{2}$ protons, both $\Delta \chi_{\mathrm{C}-\mathrm{c}}$ and the polar effect contribute predominantly to the chemical shift as well as in the case of isotactic PVC. The $\Delta \varphi$ dependence of the chemical shift of the planar zigzag form is shown using the stick spectrum in Figure 10(b)-(d) together with the observed one (a), where the same values of $\Delta \chi_{\mathrm{C}-\mathrm{C}}, \Delta \chi_{\mathrm{C}-\mathrm{C} 1}$ and $\mu_{\mathrm{C}-\mathrm{C} 1}(1.72 D)$ were used
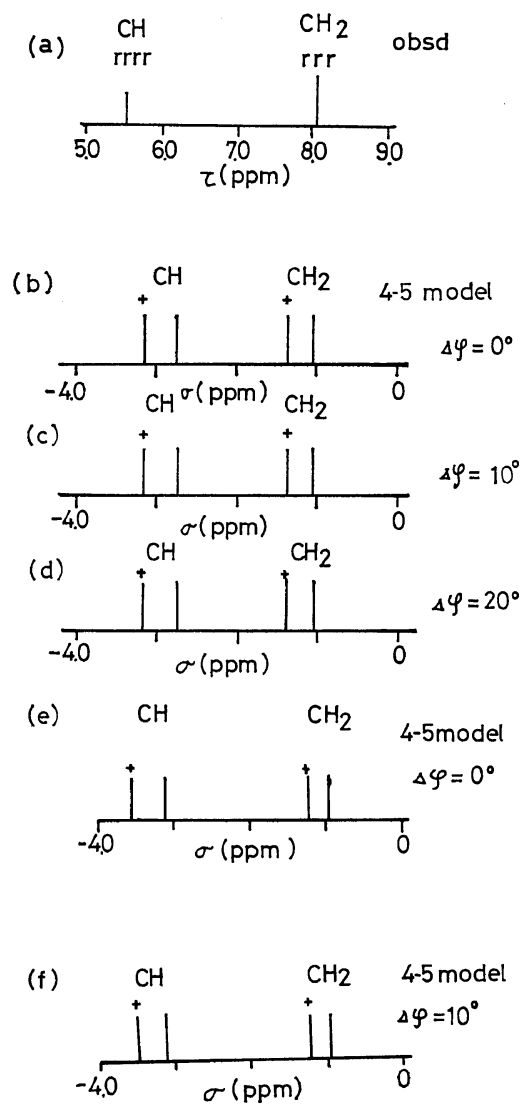

Figure 10. The stick spectra of syndiotactic poly(vinyl chloride): (a) observed ${ }^{16}$, in pentachloroethane, at $140^{\circ} \mathrm{C}(220 \mathrm{MHz}) ;($ b) $-($ d) calculated: $\mu_{\mathrm{C}-\mathrm{C} 1}=1.72 D$; (e) and (f) calculated, $\mu_{\mathrm{C}-\mathrm{C} 1}=1.84 D$. |, $\Delta \chi_{\mathrm{C}-\mathrm{C}}=5.5 \times 10^{-30} \mathrm{~cm}^{3} ; \dagger, \Delta \chi_{\mathrm{C}-\mathrm{C} 1}=9.1 \times 10^{-30} \mathrm{~cm}^{3}$.

as in the case of DCP. The rotational angle deviated from $\varphi_{t}=0^{\circ}$ as in the case of isotactic PVC. The chemical shifts of the $\mathrm{CH}_{2}$ and $\mathrm{CH}$ protons of 4-5 model change only slightly to higher field with increasing of $\Delta \varphi$. However the difference in the calculated chemical shift between the $\mathrm{CH}_{2}$ and $\mathrm{CH}$ protons is too small, as compared with the observed results. As aforementioned, this discrepancy could be improved by using a larger value of $\mu_{\mathrm{C}-\mathrm{C}}(1.84 \mathrm{D})$, which contributes largely to the chemical shift of the $\mathrm{CH}$ proton. These results are shown in Figure 10(e) and (f). The agreement between the calculated and observed results is better than (b) and (c). The $\Delta \varphi$ and $\Delta \chi_{\mathrm{C}-\mathrm{C}}$ dependences of the chemical shift are small. The difference in the 


\section{Ando, A. Nishioka, and S. Watanabe}

chemical shift between the $\mathrm{CH}_{2}$ and $\mathrm{CH}$ protons depends predominantly on the value of $\mu_{\mathrm{C}-\mathrm{Cl}}$.

Some typical calculated chemical shifts of isotactic and syndiotactic PVC's are shown in Figure 11, selected from Figures 7 and 10 in order to compare with the observed results. Figure 11(a) shows the observed spectrum. ${ }^{16}$ In Figure 11(b), $\Delta \varphi=0^{\circ}$ and $1.84 \mathrm{D}$ was used as $\mu_{\mathrm{C}-\mathrm{C} 1}$. The signals of the anti and racemic $\mathrm{CH}_{2}$ protons respectively tend to overlap with each other. In Figure 11(c), $\Delta \varphi=10^{\circ}$ and $1.84 D$ was used as $\mu_{\mathrm{C}-\mathrm{Cl}}$. Each signal of the anti and racemic $\mathrm{CH}_{2}$ protons is separated from each other. The stick spectrum $11(\mathrm{c})$ is more reasonable than the spectrum 11(b) in comparison with the observed spectrum 11(a). In the spectrum 11 (d) $\Delta \varphi=10^{\circ}$ and $0^{\circ}$ were used for isotactic and syndiatactic PVC's respectively. The anti and rasemic $\mathrm{CH}_{2}$ protons more separate from each other than in spectrum $11(\mathrm{c})$ and is close to the observed results. It is found that $\Delta \varphi$ plays an important role for the chemical shift of PVC as well as in the case of polypropylene. ${ }^{42}$

From the results described above it could be
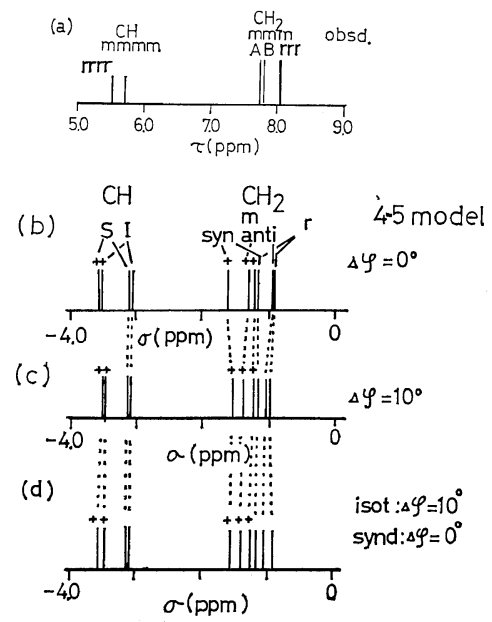

Figure 11. The stick spectra of poly(vinyl chloride): (a) observed ${ }^{16}$, in pentachloroethane, at $140^{\circ} \mathrm{C}(220$ $\mathrm{MHz})$; (b) calculated, $\mu_{\mathrm{C}-\mathrm{Cl}}=1.84 D\left(\mid, \Delta \chi_{\mathrm{C}-\mathrm{C}}=\right.$ $\left.5.5 \times 10^{-30} \mathrm{~cm}^{3}, \dagger, \Delta \chi_{\mathrm{C}-\mathrm{C}}=9.1 \times 10^{-30} \mathrm{~cm}^{3}, \Delta \varphi=0^{\circ}\right)$; (c) calculated, $\mu_{\mathrm{C}-\mathrm{Cl}}=1.84 \mathrm{D}\left(\mid, \Delta \chi_{\mathrm{C}-\mathrm{C}}=5.5 \times 10^{-30}\right.$ $\mathrm{cm}^{3}, \dagger, \Delta \chi_{\mathrm{C}-\mathrm{C}}=9.1 \times 10^{-30} \mathrm{~cm}^{3}, \Delta \chi_{\mathrm{C}-\mathrm{C} 1}=5.0 \times 10^{-30}$ $\mathrm{cm}^{3}, \Delta \varphi=10^{\circ}$; (d) calculated, $\mu_{\mathrm{C}-\mathrm{Cl}}=1.84 \mathrm{D} \quad($, $\Delta \chi_{\mathrm{C}-\mathrm{C}}=5.5 \times 10^{-30} \mathrm{~cm}^{3}$, †: $\Delta \chi_{\mathrm{C}-\mathrm{C}}=9.1 \times 10^{-30} \mathrm{~cm}^{3}$, $\left.\Delta \chi_{\mathrm{C}-\mathrm{C} 1}=5.0 \times 10^{-30} \mathrm{~cm}^{3}\right) ; \Delta \varphi=10^{\circ}$ for isotactic PVC, $\Delta \varphi=0^{\circ}$ syndiotactic, PVC. interpreted theoretically that the signal of racemic $\mathrm{CH}_{2}$ appears at higher field than that of syndiotactic $\mathrm{CH}$. These results coincide with the results of DCP shown above.

As shown above the chemical shifts of isotactic and syndiotactic PVC's were calculated separately from each other and the influence of the isotactic placement in atactic PVC was not taken in account. Thus for discussing the chemical shifts of PVC in more detail we must take this effect into account and the "external" solvent effect neglected in this paper.

\section{CONCLUSION}

Above results are conclusively summarized as follows;

(a) It was predicted from the calculated chemical shifts using the preferred conformations that the anti proton of the $\mathrm{CH}_{2}$ in meso DCP and isotactic PVC together appears at higher field than the syn proton. The calculated results that the $\mathrm{CH}_{2}$ and $\mathrm{CH}$ in racemic DCP or syndiotactic DCP together appear at higher and lower fields than those in meso DCP or isotactic PVC respectively, coincide with the observed results. Also the calculated result that the $\mathrm{CH}_{3}$ in racemic DCP appears at higher field than that of meso DCP coincides with the observed results.

(b) From comparison of the calculated and observed proton chemical shifts in DCP and PVC it was found that the polar effect predominantly contributes to the chemical shift.

(c) Every carbon nuclei in meso DCP appears at higher field than corresponding one in racemic DCP both theoretically and experimentally.

(d) The TT form in racemic DCP is more stable than the $G G$ form by $1.97 \mathrm{kcal} / \mathrm{mol}$. This value compares reasonably with other data.

Acknowledgement. The authors gratefully acknowledge the help made by Dr. T. Hirano of the University of Tokyo during the calculation of the extended Hückel method and the helpful comments made by Dr. N. Nakagawa of the University of Electro-Communication. 
The Chemical Shifts of DCP and PVC.

\section{REFERENCES}

1. U. Johnsen, J. Polym. Sci., 54, 56 (1961).

2. F. A. Bovey and G. V. D. Tiers, Chem. Ind. (London), 826 (1962).

3. R. Chûjô, S. Satoh, T. Ozeki and E. Nagai, J. Polym. Sci., 61, 512 (1962).

4. W. C. Tincher, ibid., 62, 5148 (1962).

5. F. A. Bovey, E. W. Anderson, D. C. Douglass, and J. A. Manson, J. Chem. Phys., 39, 1199 (1963).

6. S. Satoh, J. Polym. Sci., Part A, 2, 5221 (1964).

7. W. C. Tincher, Makromol. Chem., 85, 20 (1965).

8. T. Yoshino and K. Komiyama, J. Polym. Sci., Part B, 3, 311 (1965).

9. O. C. Böckman, ibid, Part A, 3, 3399 (1965).

10. B. Schneider, J. Štokr, D. Doskočilova, M. Kolinsky, S. Sykora, and D. Lim, Preprint, International Symposium Makromolecular Chemistry Prague, 1965, 1966, p 599.

11. J. Bargon, K.-H. Hellwege, and U. Johnsen, ibid, 95, 187 (1966).

12. K. C. Ramey, J. Phys. Chem., 70, 2525 (1966).

13. S. Enomoto, M. Asahina, and S. Satoh, $J$. Polrm. Sci., Part A-1, 4, 1373 (1966).

14. F. A. Bovey, F. P. Hood, E. W. Anderson, and R. L. Kornegay, J. Phys. Chem., 71, 312 (1967).

15. U. Johnsen and K. Kolbe, Kolloid-Z., 221, 64 (1967).

16. F. Heatley and F. A. Bovey, Macromolecules, 2, 241 (1969).

17. R. Shimanouchi and M. Tasumi, Spectrochim. Acta, 17, 755 (1961).

18. D. Lim and M. Kolinsky, J. Polym. Sci., 53, 173 (1961).

19. T. Shimanouchi, M. Tasumi, and Y. Abe, Makromol. Chem., 86, 43 (1965).

20. D. Doskočilova, J. Polym. Sci., Part B, 2, 421 (1964).

21. P. E. McMahon and W. C. Tincher, J. Mol. Spectrosc., 15, 180 (1965).

22. T. Shimanouchi, Pure Appl. Chem., 12, 287 (1966).

23. Y. Abe, M. Tasumi, T. Shimanouchi, S. Satoh, and Chûjô, J. Polym. Sci., Part A-1, 4, 1413 (1966).

24. D. Doskočilova, J. Štokr, B. Schneider, H. Pivcova, M. Kolinsky, J. Petranek, and D. Lim, ibid., Part C, 215 (1967).

25. P. J. Flory and A. D. Williams, J. Amer. Chem. Soc., 91, 3118 (1969).

26. R. Hoffmann, J. Chem. Phys., 39, 1397 (1963).

27. J. A. Pople, W. G. Schneider, and H. J. Bernstein, "High Resolution Nuclear Magnetic Resonance", McGraw Hill Book Co., Inc., New York N. Y., 1957, Section 7.4.

28. W. E. Lamb, Phys. Rev., 60, 817 (1941).

29. H. M. McConnell, J. Chem. Phys., 27, 226 (1957).

30. A. A. Bothner-By and C. Naar-Colin, Ann. New York Acad. Sci., 70, 833 (1958).

31. I. Ando and A. Nishioka, Preprint of the 10th Symposium on NMR, Tokyo, 7 (1971).

32. T. Schaefer and T. Yonemoto, Can. J. Chem., 42, 2318 (1964).

33. A. D. Buckingham, Can. J. Chem., 38, 300 (1960).

34. H. A. Skinner and H. O. Pritchard, Trans. Faraday Soc., 49, 1254 (1953); H. O. Pritchard and H. A. Skinner, Chem. Rev., 55, 745 (1955).

35. L. Pauling, "Nature of Chemical Bond", Cornell University Press, New York N. Y., 1960.

36. C. J. Carman, A. R. Tarpley, and J. H. Goldstein, J. Amer. Chem. Soc., 93, 2864 (1971).

37. Y. Inoue, I. Ando and A. Nishioka, Polymer J. 3, 246 (1972).

38. T. Yonezawa, I. Morishima and H. Kato, Bull. Chem. Soc. Japan, 39, 1398 (1966).

39. I. Ando and A. Nishioka, Polymer J., 1, 288 (1970).

40. T. Shimanouchi, Kobunshi (High Polymers), 15, 776 (1966).

41. P. J. Flory, "Statistical Mechanics of Chain Molecules", Interscience Pub., New York N. Y., 1969, Chapter VI.

42. I. Ando and A. Nishioka, Polymer J., 2, 161 (1971). 